\title{
Isolation and Screening of Microorganisms with Potential for Biotransformation of Terpenic Substrates
}

\author{
Mário César Jucoski Bier, Sabrina Poletto, Vanete Thomaz Soccol, Carlos Ricardo Soccol \\ and Adriane Bianchi Pedroni Medeiros* \\ Divisão de Engenharia de Bioprocessos e Biotecnologia; Universidade Federal do Paraná; 81531-990; Curitiba - \\ PR - Brasil
}

\begin{abstract}
The objective of the present work was to isolate and select strains with potential to perform the biotransformation of terpenic substrates. Microorganisms obtained from a collection culture and also isolated from a natural source of terpene substrate were tested. Seventeen strains were selected by their resistance to terpenes in potato dextrose agar containing up to $1 \%$ of limonene or $\alpha$-pinene and $\beta$-pinene $(1: 1)$. Subsequently, 10 strains were selected by their capacity of using these terpenes as sole carbon source in a mineral medium. The biotransformation capacity of these strains was tested and the products obtained were identified by GC-MS.
\end{abstract}

Key words: Aroma; Flavour; Limonene; $\beta$-pinene; Biotransformation

\section{INTRODUCTION}

Aroma and fragrance incorporated in foods, perfumes and cosmetics have high value in the world market, leading towards the selection of species commercially cultivated in quantity and quality of volatile substances (Santos et al., 2003). Generally, many natural flavour materials had been obtained from animals and higher plants. Supplies of many of these materials have dwindled due to social, economic, and political factors, and conservation, wildlife protection and industrial growth. In recent years, there has been a growing demand for flavouring materials from natural sources. The use of microorganism may offer an alternative method for producing natural flavour and fragrances (Scharpf et al., 1986). The biotechnological interventions offer significant advantages in relation to the traditional extraction of plant materials which include high final product specificity, production through all the year and the use of alternative raw-materials such as agroindustrial residues as substrates for the cultivation of these microbes. Currently, most food flavoring compounds are produced via chemical synthesis or extraction from natural materials (Rossi et al., 2009). However, recent market surveys have demonstrated that consumers prefer foodstuff that can be labeled as natural. The industrial production of aromas corresponds of $25 \%$ of the food additives world market (Couto and Sanróman, 2006). Besides that, flavors present additional sensorial characteristics, antimicrobial activity, antioxidant activity, anti-inflammatory properties, fat reduction and arterial pressure regulation (Berger, 2009).

*Author for correspondence: adrianebpm@ufpr.br 
With more than 22,000 individual identified compounds, terpenes represent the largest group of natural products. Biotransformation of terpenes represents a very attractive alternative for the production of aromas, because it takes place under mild conditions, does not generate toxic wastes and allows producing "natural" aromas that can be used as fragrances and flavors in the industry (Dionísio et al., 2009). Some derivatives of limonene are $\alpha$-terpineol, perillyl alcohol, carveol, carvone and menthol. Some biotransformation products of $\alpha$-pinene are verbenol, $\alpha$-terpineol, pinocarveol and mirtenol. Pinocarveol, pinocamphone and mirtenol are some other compounds obtained by the biotransformation of $\beta$-pinene (Bicas et al., 2008). Thus, many interesting aroma compounds could be derived from the terpenes. Terpenes are also excellent alternative precursors. According to Aleu and Collado (2001), the biotransformation of terpenes represents a very attractive alternative for the production of natural aroma compounds. However, many of the rules that define biotransformations are not well understood and there are many chemical reactions for which there is no equivalent bioconversion.

Fungi secrete a large variety of substances responsible for aroma. In general, fungi and yeasts responsible for the aroma are predominantly aerobic and utilize carbohydrates and organic acids and rarely alcohol as their main source of carbon (Scharpf et al., 1986). Many studies have been performed recently in terms of production of aroma using terpenes, resulting in wide variety of products (Oliveira and Strapasson, 2000; Aleu and Collado, 2001; Demyttenaere and Kimpe, 2001; Menéndez et al., 2002; Lindmark-Henriksson et al., 2003; Bicas and Pastore, 2009; Dioníso et al., 2009). The processing of agro-industrial products generates large quantities of waste, whose accumulation has been a serious problem of environmental pollution. The biotransformation can be reached not only from artificial precursors, but from natural sources that have been considered waste.

This work aimed to isolate fungi and yeasts cultures which could be used for the production of aroma compounds.

\section{MATERIAL AND METHODS}

\section{Microorganisms}

Twenty microorganisms were obtained from the Culture Collection of the Biotechnological Process Laboratory of the Federal University of Paraná (UFPR) (Table 1). The strains had their code number based on the material source, while its letters represented the different isolates among the same sources.

Table 1 - Laboratorial strains used in order to test the terpene resistance.

\begin{tabular}{cccc}
\hline Specie & Code & Specie & Code \\
\hline Rhizopus microsporus & 1,2 & Rhizopus stolonifer & 14 \\
Rhizopus delemar & 3,13 & Rhizopus formosa & 20 \\
Rhizopus oryzae & 4,12 & Trichoderma sp & 9,10 \\
Rhizopus oligosporus & 5 & Pichia stipitis & 16 \\
Rhizopus circicans & 6 & Kluyveromyces marxianus & 17 \\
Rhizopus sp & 7 & Pachysolen tannophylus & 18 \\
Rhizopus arrhizus & $8,11,15$ & Ceratocystis fimbriata & 19 \\
\hline
\end{tabular}

\section{Isolation}

The microorganisms were isolated from natural substrates obtained from reforestation area of the Arauco Forest do Brasil (Campo do Tenente, Paraná). Samples of bark, needles and cones were collected in sterile glass. The isolation occurred by scraping the material with a platinum loop and inoculating into sterile liquid medium. It was also suspended in peptone water and subsequently inoculated on the surface of Petri dishes containing potato dextrose agar (PDA) and nutrient agar.

\section{Inoculum Development}

The fungal spores were transferred aseptically with a loop to Erlenmeyer flasks containing $40 \mathrm{~mL}$ of PDA and incubated at $30^{\circ} \mathrm{C}$ during seven days. Spores suspension was obtained by adding $25 \mathrm{~mL}$ of sterile distilled water with a drop of Tween 80 . Yeast and malt extract (YM) medium was used to prepare the inocula for the bacteria and yeasts $(50$ $\mathrm{mL}$ in Erlenmeyer flasks) and incubating at $30^{\circ} \mathrm{C}$ for 48 hat $120 \mathrm{rpm}$. 


\section{Resistance Screening}

The terpene resistant microorganisms were selected based on Demyttenaere and Kimpe (2001) and Maróstica Junior (2006). The culture medium contained $(\mathrm{R})-(+)$-limonene or $\alpha$-pinene and $\beta$ pinene (1:1). The concentrations tested were $0.2 \%$ (diluted in ethanol) and $1 \%$. The cultures were incubated at $30^{\circ} \mathrm{C}$ for seven days and were compared to the control sample, which did not contain the terpenes.

\section{Carbon Source Test}

The inoculum rate was $10^{7}$ cells or spores in 40 $\mathrm{mL}$ of mineral medium. The medium (Bicas and Pastore, 2007) contained (g/L) (NH4) ${ }_{2} \mathrm{SO}_{4}$ 5.00; $\left(\mathrm{NH}_{4}\right)_{2} \mathrm{HPO}_{4}$ 1.42; $\mathrm{NaCl} 0.50 ; \mathrm{MgSO}_{4} .7 \mathrm{H}_{2} \mathrm{O} 0.40$; $\mathrm{CaCl}_{2}$ 0.60; KCl 2.15; $\mathrm{FeSO}_{4} .7 \mathrm{H}_{2} \mathrm{O} 0.01 ; \mathrm{ZnSO}_{4}$ $0.01 ; \mathrm{CuSO}_{4} 0.01$ and $400 \mu \mathrm{L}(1 \%, \mathrm{v} / \mathrm{v})$ of limonene or $200 \mu \mathrm{L} \alpha$-pinene and $200 \mu \mathrm{L} \beta$-pinene $(1 \%, \mathrm{v} / \mathrm{v})$. A mineral medium containing equivalent quantity of glucose in place of the terpenes was used as the control. The biomass was quantified by dry weight. For the fungi, the biomass was filtered, whereas centrifugation was used for the yeasts. This experiment was carried out at $30^{\circ} \mathrm{C}$ and $120 \mathrm{rpm}$ for seven days.

\section{Biotransformation Experiments}

Aroma production was carried out under the aforesaid medium and conditions with $20 \mathrm{~g} / \mathrm{L}$ of glucose for filamentous fungi and $10 \mathrm{~g} / \mathrm{L}$ for yeasts. Limonene, $\alpha$-pinene or $\beta$-pinene were used as the substrates for biotransformation at $1 \%(\mathrm{v} / \mathrm{v})$. Four $\mathrm{mL}$ of the fermented broths were extracted with $2.0 \mathrm{~mL}$ of hexane and analysed in gas chromatography. The products generated from the terpene conversion were further identified in GCMS.

\section{Gas Chromatography}

The methodology used for aroma compounds analysis was based on Demyttenaere, Vanorschelde and Kimpe (2004). A Shimadzu gas chromatograph GC-17, equipped with a column HP-5 (30 m x $0,25 \mathrm{~mm}$ ) was used. Injector was maintained at $250^{\circ} \mathrm{C}$ and detector at $280^{\circ} \mathrm{C}$. Temperature was programmed at $40^{\circ} \mathrm{C}$, increasing $5^{\circ} \mathrm{C} / \mathrm{min}$ until $150^{\circ} \mathrm{C}, 10^{\circ} \mathrm{C} / \mathrm{min}$ until $170^{\circ} \mathrm{C}$ and $30^{\circ} \mathrm{C} / \mathrm{min}$ until the final temperature of $250^{\circ} \mathrm{C}$. Injection volume was $1 \mu \mathrm{L}$ and a split ratio 1:40. Carrier gas was nitrogen at $3.3 \mathrm{~mL} / \mathrm{min}$.

\section{GC-MS}

The identification of the compounds was performed on a Varian GC-MS CP 3800/Saturn 2000 equipped with CP-Sil $8 \mathrm{CB}$ column (30 m x $0,25 \mathrm{~mm})$. Initial temperature was $60^{\circ} \mathrm{C}$ with temperature elevation of $3^{\circ} \mathrm{C} /$ minute until $250^{\circ} \mathrm{C}$. Split was $1 / 200$. Scan range was from 30 to 500 $\mathrm{m} / \mathrm{z}$. The identification was performed according to Adams (2009). The linear and theoretical retention indices confirmed the identifications.

\section{RESULTS AND DISCUSSION}

\section{Isolation}

Twenty one strains were successfully isolated among which two were yeasts, five were bacteria and fourteen were fungi. The yeasts were the Y4a and $\mathrm{Y} 4 \mathrm{~b}$. The bacterial strains were named B1a, B1b, B1c, B1d and B2a. The fungal cultures showed different behaviour such as sporulation time and colour.

\section{Strains Resistance Selection}

Generally, the minimum inhibitory concentration (MIC) of limonene against some bacteria and yeasts are lower than $2 \%$, although some fungi and bacteria could support higher concentrations. In biotransformation processes, the usual limonene concentration applied varies from 0.2 to $1 \%$ (Bicas and Pastore, 2007). For this reason, the maximum concentration used in the experiments was $1 \%$. Since the genera Pinus presents a high concentration of $\alpha$ and $\beta$-pinene (Ludley et al., 2009; Kupcinskiene; Stikliene and Judzentiene, 2008; Lin; Owen and Peñuelas, 2007), the high number of resistant strains among the ones isolated (Table 2) could be explained. Nevertheless, the strains from the laboratory collection also presented good results (Table 3). These strains have already been reported as aroma production microorganisms (Rossi et al., 2009; Christen et al., 2000; Medeiros et al., 2000; Lindmark-Henriksson et al., 2003). 
Table 2 - Selection of terpene resistant isolate microorganisms, where “+” is growth positive and "_“ means no growth. The terpene concentration was $1 \%(\mathrm{v} / \mathrm{v})$.

\begin{tabular}{ccc}
\hline Strain & Limonene & $\boldsymbol{\alpha}$ and $\beta$-pinene \\
\hline 1a & + & + \\
1b & - & + \\
1c & - & + \\
2a & + & + \\
2b & + & + \\
2c & + & + \\
2d & + & + \\
3a & + & + \\
3b & + & + \\
3a & + & + \\
$4 \mathrm{a}$ & + & - \\
$4 \mathrm{~b}$ & - & + \\
4c & + & + \\
$4 \mathrm{~d}$ & + & - \\
Y4a & - & + \\
Y4b & + & + \\
B1a & + & + \\
B1b & + & - \\
B1c & - & + \\
B1d & + & - \\
B2a & - & + \\
\hline
\end{tabular}

Table 3 - Selection of terpene resistant laboratorial microorganisms, where "+” is growth positive and "-“ means no growth or faster sporulation. Terpene concentration was $1 \%(\mathrm{v} / \mathrm{v})$.

\begin{tabular}{ccc}
\hline Strain & Limonene & $\boldsymbol{\alpha}$ and $\beta$-pinene \\
\hline 1 & - & + \\
2 & + & - \\
3 & - & + \\
4 & + & + \\
5 & + & + \\
6 & + & + \\
7 & - & - \\
8 & - & + \\
9 & + & + \\
10 & + & + \\
11 & + & + \\
12 & - & + \\
13 & - & + \\
14 & + & + \\
15 & + & + \\
17 & - & - \\
18 & - & + \\
20 & + & + \\
\hline
\end{tabular}

The different Rhizopus strains presented interesting results. The mycelium height increased significantly when compared to the control sample, varying from $152.6 \%$ (strain 12) to $552.4 \%$ (strain 4 ) in the presence of limonene (Fig. 1). In the presence of $\alpha$ and $\beta$-pinene (Fig. 2), the height did not increase as much as with the limonene. However the mycelium's height still reached $364.3 \%$ (strain 4 ).

Despite growing in the medium containing the terpenes tested, the studied strains, in general, needed $24 \mathrm{~h}$ to grow on the medium containing $\alpha$ and $\beta$-pinene when compared to the control medium. On average, they needed $24 \mathrm{~h}$ more in the 
medium containing limonene than in medium containing $\alpha$ - and $\beta$-pinene. Also, most of them took longer time to sporulate, which indicated that the presence of terpenes did not make the environment less propitious for growth, but led the strains to a longer lag phase. Martins et al., (2005) reported the importance to compare the development of fungi in different environments, because the fungi reacted differently to stimulus induced by the composition of the medium. Thus, it is possible to infer the importance of the results obtained from the behavior of microorganisms observed during the selection. Thus, the strains whose sporulation occurred sooner in the presence of the terpenes were considered negatively affected by the terpenes and consequently not used in further experiments.

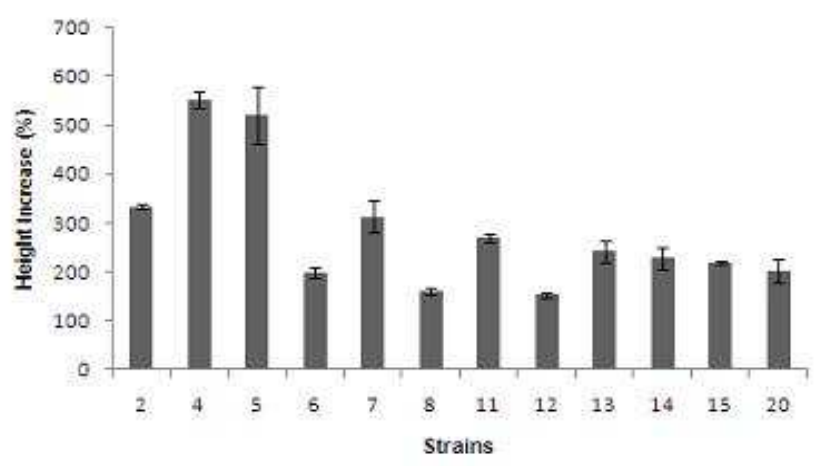

Figure 1 - Increase of the Rhizopus mycelium height in the presence of limonene in comparison to the control medium $(\%)$.

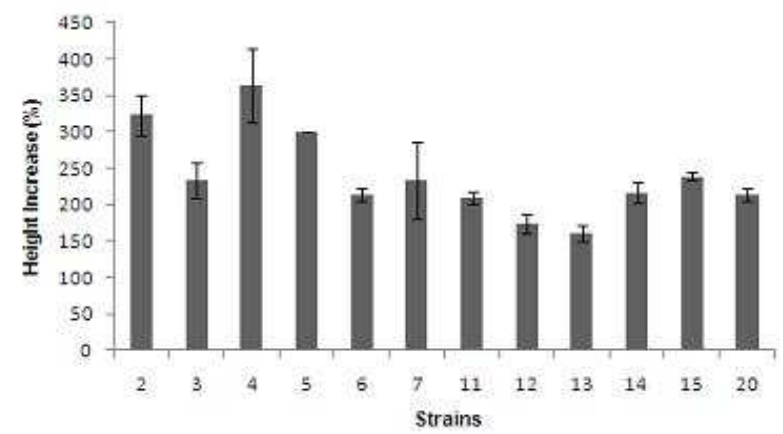

Figure 2 - Increase of the Rhizopus mycelium height in the presence $\alpha$ and $\beta$-pinene in comparison to the control medium $(\%)$.

As stated by Bicas and Pastore (2007), the substrate resistance does not guarantee a high biotransformation activity, but it is an essential characteristic to a biotransforming agent. That way, this step was configured as an important part of the study.

\section{Carbon Source Test}

In order to find a microorganism capable of biotransforming certain substrate, it is necessary to study the response of the microorganism response when grown with it. The first step to find the adequate biocatalysts is the screening of those resistant microorganisms that can use the substrate as sole carbon source (Bicas et al., 2009). This indicates the existence of a substrate-degrading metabolic pathway, which can possibly accumulate the interesting intermediate products. In the medium containing limonene as sole carbon source, the best results of biomass production (Fig. 3) were obtained by the strains $4 \mathrm{~d}(1 \mathrm{~g} / \mathrm{L}), 4 \mathrm{a}$ $(0.95 \mathrm{~g} / \mathrm{L}), 2 \mathrm{~b}(0,81 \mathrm{~g} / \mathrm{L})$, as like by the yeasts 16 $(1.05 \mathrm{~g} / \mathrm{L}-$ Pichia $)$ and $\mathrm{Y} 4 \mathrm{~b}(0,86 \mathrm{~g} / \mathrm{L})$, and 5 (0.78g/L - Rhizopus). Later, strains $2 \mathrm{c}(0.72 \mathrm{~g} / \mathrm{L})$, $4 \mathrm{c}(0.74 \mathrm{~g} / \mathrm{L})$ and $3 \mathrm{a}(0.63 \mathrm{~g} / \mathrm{L})$ were also tested in the product screening in further steps. For the $\alpha$ and $\beta$-pinene carbon test, the best results (Fig. 4) were obtained for the strains $16(1.14 \mathrm{~g} / \mathrm{L}), \mathrm{Y} 4 \mathrm{~b}$ 
$(0.89 \mathrm{~g} / \mathrm{L}), \quad 4 \mathrm{a} \quad(0.81 \mathrm{~g} / \mathrm{L}), \quad 5 \quad(0.90 \mathrm{~g} / \mathrm{L})$ and 19 $(0.92 \mathrm{~g} / \mathrm{L})$. Thus better results were obtained in the mineral medium containing $\alpha$ - and $\beta$-pinene, in which the strains presented higher growth. This could be further confirmed when the strains were grown in the medium containing Pinus waste.

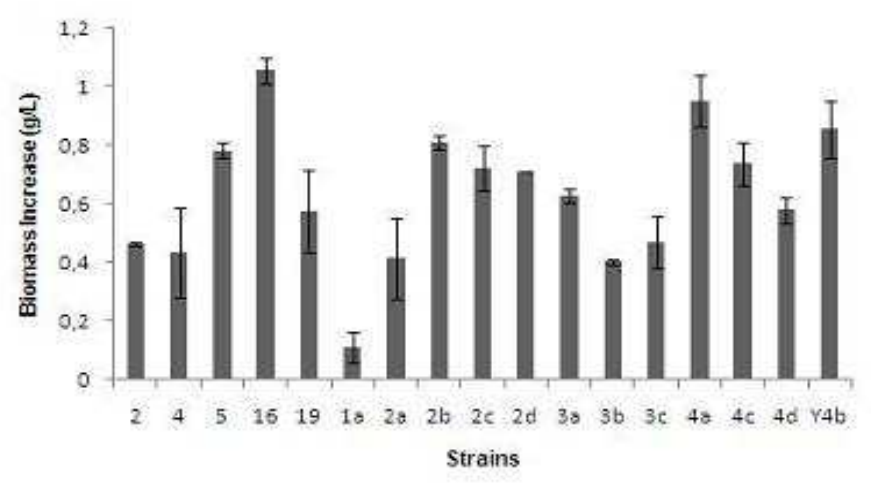

Figure 3 - Biomass concentration using limonene as sole carbon source (1\% v/v).

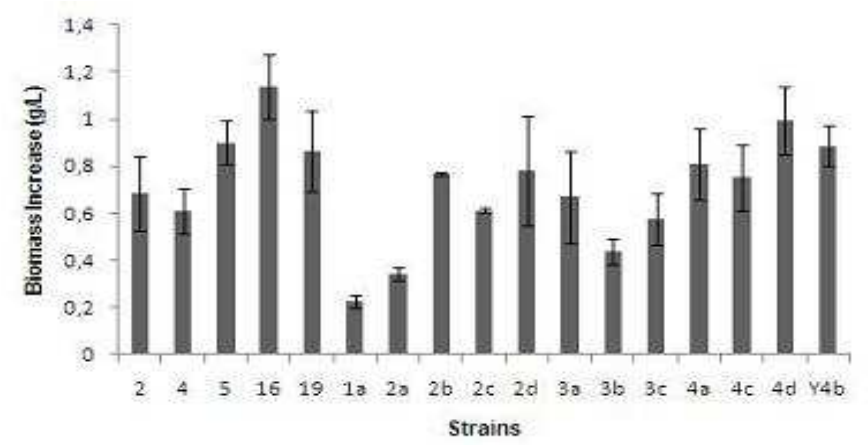

Figure 4 - Biomass concentration using $\alpha$ and $\beta$-pinene (1:1) as sole carbon source ( $1 \% \mathrm{v} / \mathrm{v})$.

Therefore, the results obtained as above seemed peculiar. The strains 2 and 4 , the ones that showed the highest mycelia height increase during the selection step, now presented poor growth in the medium containing terpene as carbon source when compared to the strain 5. They could not grow in the mineral liquid medium or in the solid medium used in the resistance test.

\section{Product Screening}

Ten of the best strains obtained from the previous steps were tested by their capacity of biotransforming limonene, $\alpha$-pinene and $\beta$-pinene. None showed capacity of biotransforming $\alpha$ pinene, while only the yeast $\mathrm{Y} 4 \mathrm{~b}$ presented a product for $\beta$-pinene fermentation. Four strains showed capacity of biotransforming limonene.
Sixteen compounds were identified (Table 4), which included carveol, carvone, perillyl alcohol and perillyl aldehyde,which were aroma compounds of great interest. Carvone is defined by Carvalho and Fonseca (2006) as having sweet spearmint odour. Carvone has importance as fragrance and flavor, relevance in the medical field and other applications. Like carvone, perillyl alcohol is a limonene derivative with higher value. Its importance in cancer threads is becoming defunded. Carveol and its isomers such as dihydrocarveol and carvone oxide are in the metabolic pathway of carvone; the same way perillyl aldehyde is in the methabolic pathway of perillyl alcohol, as showed by Maróstica Júnior and Pastore (2007). 
Table 4 - Compounds identified by GC-MS in the fermented medium of the selected strains. Lin means limonene mineral medium and $\beta$-p is for $\beta$-pinene.

\begin{tabular}{|c|c|c|c|c|c|}
\hline Compound / Strain and medium & $51 \%$ Lim & $161 \%$ Lim & $3^{a} 1 \%$ Lim & Y4b 1\% Lim & Y4b 1\% $\beta-p$ \\
\hline$\alpha$-fenchene & & & & & $\mathrm{X}$ \\
\hline Sabinene & & & & $\mathrm{X}$ & $\mathrm{X}$ \\
\hline Trans-sabinene hydrate & & & & $\mathrm{X}$ & \\
\hline Trans-p-menta- 2,8 dien- 1 ol & & & $\mathrm{X}$ & & \\
\hline Cis-p-menta-2,8 dien-1ol & & & $\mathrm{X}$ & & \\
\hline 3-methyl-2-acrolein-puril & & $\mathrm{X}$ & & & \\
\hline Isomer of carveol & $\mathrm{X}$ & $\mathrm{X}$ & $\mathrm{X}$ & & \\
\hline Dihydrocarveol & & $\mathrm{X}$ & & $\mathrm{X}$ & \\
\hline Trans-Carveol & & $\mathrm{X}$ & $\mathrm{X}$ & & \\
\hline Cis-Carveol & & $\mathrm{X}$ & $\mathrm{X}$ & & \\
\hline Carvone & & $\mathrm{X}$ & $\mathrm{X}$ & & \\
\hline Acetate trans-sabinene hydrate & & $\mathrm{X}$ & & $\mathrm{X}$ & \\
\hline Cis-carvone oxide & & $\mathrm{X}$ & & & \\
\hline Perillyl aldehyde & & $\mathrm{X}$ & & & \\
\hline Limonen-10-ol & $\mathrm{X}$ & & & & \\
\hline Perillyl alcohol & $\mathrm{X}$ & $\mathrm{X}$ & & & \\
\hline Guaiol & & & & $\mathrm{X}$ & $\mathrm{X}$ \\
\hline
\end{tabular}

Carvone production using limonene as precursor has already been reported in some studies (Carvalho and Fonseca, 2003; Vanek, Valterova and Valsar, 1999) as like perillyl alcohol production (Oliveira and Strapasson, 2000; Menéndez et al., 2002). Some of the products found in the fermentation medium have not been described as limonene or $\beta$-pinene derivatives; thus, their presence cannot be attributed to biotransformation effects. The presence of sabinene, guaiol, $\alpha$-fenchene and derivatives in the medium fermented by the yeast Y4b should be further investigated.

\section{CONCLUSIONS}

Twenty one newly isolated strains and the 20 from the laboratory collection were tested for terpene resistant. Among the isolated ones, 15 were resistant to limonene at a concentration of $1 \%$, and 16 for $1 \%$ of $\alpha$ - and $\beta$-pinene (1:1). Eleven laboratory collection strains were considered resistant to $1 \%$ of limonene, while 16 were considered resistant to $1 \% \alpha$ - and $\beta$-pinene. The isolated strains $2 \mathrm{~b}, 3 \mathrm{a}, 4 \mathrm{a}, 4 \mathrm{~d}$ and $\mathrm{Y} 4 \mathrm{~b}$ and the collection strains 5, 16 and 19 showed good potential in carbon source study and during some of the steps of the related study, many cultures showed aroma modification detected by gas chromatography. Interesting compounds such as carvone, perillyl alcohol and others were produced from the strains 5, 16, 3a and Y4b.

\section{ACKNOWLEDGMENTS}

We are grateful to CAPES (Brazil) for the financial support. We are also very grateful to LACAUT $_{\text {ETS }} /$ UFPR for providing and supporting at the GC-MS analysis.

\section{REFERENCES}

Adams, R. P. (2009), Identification of Essential Oil Components by Gas Chromatography/Mass Spectrometry. 4 ed. Allured Publishing Corporation, Carol Stream.

Aleu, J. and Collado, I. G (2001), Biotransformations by Botrytis species. J Mol Catal B: Enzym., 13, 7793.

Berger, R. G (2009), Biotechnology of flavours - the next generation. Biotechnol. Lett., 31, 1651-1659.

Bicas, J. L. and Pastore, G. M (2007), Isolation and Screening of D-Limonene-Resistant Microorganisms. Brazilian Journal of Microbiology. 38, 563-567.

Bicas, J. L., Fontainelle, P., Pastore, G. M. and Larroche, C. (2008), Characterization of monoterpene biotransformation in two pseudomonads. $J$ Appl Microbiol., 105, 1991-2001.

Bicas, J. L., Dionísio, A. P., Pastore, G. M. (2009), Biooxidation of Terpenes: An Approach for the Flavor Industry. Chem Rev., 109, 4518-4531. 
Carvalho, C. C. R., de and Fonseca, M. M. R., da. (2003), Towards the bio-production of transcarveol and carvone form limonene: induction after cell growth on limonen and toluene. Tetrahedron: Asymmetry. 14, 3925-3931.

Carvalho, C. C. R., de and Fonseca, M. M. R., da. (2006), carvone: Why and how one bother to produce this terpene. Food Chem., 95, 413-422.

Christen, P., Brasmorski, A., Revah, S. and Soccol, C. R. (2000), Characterization of volatile compounds produced by Rhizopus strains grown on agroindustrial solid wastes. Bioresour Technol., 71, 211215.

Couto, S. R. and Sanróman, M. A. (2006), Application of solid-state fermentantion to foody industry - A review. Journal of Food Engineering. 76, 291-302.

Demyttenaere, J. and Kimpe, N. (2001), Biotransformation of terpenes by fungi: Study of the pathways involved. J Mol Catal B: Enzym., 11, 265270.

Demyttenaere J., Vanoverschelde, J. and Kimpe, N. (2004), Biotransformation of $(R)-(+)-$ and $(S)-(-)-$ citronellol by Aspergillus sp. and Penicillium sp., and the use of solid-phase microextraction for screening. J Chromatogr A., 1027, 137-146,

Dionísio, A. P., Molina, G., Bicas, J. L. and Pastore, G. M. (2009), Fungal biotransformation of terpenes. New Biotechnology., 25, supl. 1, 191.

Kupcinskiene, E.; Stikliene, A. and Judzentiene, A. (2008), The essential oil qualitative and quantitative composition in the needles of Pinus sylvestris L. growing along industrial transects. Environ Pollut., 155, 481-491.

Lin, C., Owen, S. M. and Peñuelas, J. P. (2007), Volatile organic compounds in the roots and rhizosphere of Pinus spp. Soil Biol Biochem., 39, 951-960.

Lindmark-Henriksoon, M., Isaksson, D.; Vanek, T., Valterova, I. Högbert, $H$. and Sjödin, K (2003).Transformation of terpenes using a Picea abies suspension culture. J Biotechnol., 107, 173-184.

Ludley, K. E., Jickells, S. M., Chamberlain, P. M., Whitaker, J. and Robinson, C. H. (2009), Distribution of monoterpenes between organic resources in upper soil horizons under monocultures of Picea abies, Picea sitchensis and Pinus sylvestris. Soil Biol Biochem., 41, 1-10.
Maróstica Júnior, M. R. (2006), Biotransformação de terpenos para a produção de compostos de aroma e funcionais. Tese de doutorado Campinas, Universidade Estadual de Campinas (UNICAMP), Campinas, Brasil.

Maróstica Júnior, M. R. and Pastore, G. M. (2007), Biotransformação de limoneno: uma revisão das principais rotas metabólicas. Quim Nova. 30, 382387.

Martins, I., Mello, S. C. M. de., Ávila, Z.; Pádua, R. R.; Peixoto, J. R. (2005), Produção de Colletotrichum gloeoesporiodes em meios líquidos. Circular Técnica - Embrapa. 45, 1-6.

Medeiros, A. B. P., Pandey, A. P. R.; Freitas, R. J. S., Christen, P. and Soccol, C. R. (2000), Optimization of the production of aroma compounds by Kluyveromyces marxianus in solid-state fermentation using factorial design and response surface methodology. Biochem Cell Biol., 6, 33-39.

Menéndez, P., Garcia, C., Rodriguez, P. and Heinzen, H. (2002), Enzymatic Systems Involved in Dlimonene Biooxidation. Braz Arch Biol Technol., 45, 111-114.

Oliveira, B. H. de., and Strapasson, R. A. (2000), Biotransformation of the Monoterpene, Limonene, by Fusarium verticilloid. Braz Arch Biol Technol., 43.

Rossi, S. C., Vanderberghe, L. P. S., Pereira, B. M. P., Gago, F. D., Rizzolo, J. A., Pandey, A., Soccol, C. R. and Medeiros, A. B. P. (2009), Improving fruity aroma production by fungi in SSF using citric pulp. Food Res Int., 42, 484-486.

Santos, A. C. A., Serafini, L. A and Cassel, E. Estudos de processos de extração de óleos essenciais e bioflavonóides de frutas cítricas. Caxias do Sul: Educs, 2003.

Scharpf, I. G., Seitz, E. W., Morris, A. J. and Farbood, M. I. (1986), Generation of Flavor and Odor Compounds through Fermentation Processes. In: Parliament, T. H.; Croteau, R. (ED). Biogeneration of aromas. American Chemical Society. 323-346, (Symposium Series, 317).

Vanek, T., Valterova, I. and Valsar, T. (1999), Biotransformation of (S)-(-)- and (R)-(+)-limonene using Solanum aviculare and Dioscorea deltoidea plant cells. Phytochem., 50, 1347-1351. 